\title{
BMJ Open Direct medical costs of hospitalisations for mental disorders in Shanghai, China: a time series study
}

\author{
Wenming Chen, ${ }^{1}$ Shengnan Wang, ${ }^{1}$ Qi Wang, ${ }^{1}$ Weibing Wang ${ }^{1,2,3,4}$
}

To cite: Chen W, Wang S, Wang $Q$, et al. Direct medical costs of hospitalisations for mental disorders in Shanghai, China: a time series study. BMJ Open 2017;7:e015652. doi:10.1136/ bmjopen-2016-015652

- Prepublication history for this paper is available online. To view these files please visit the journal online (http://dx.doi. org/10.1136/bmjopen-2016015652).

Received 21 December 2016 Revised 6 August 2017 Accepted 15 August 2017

\section{(a) CrossMark}

${ }^{1}$ Department of Epidemiology, School of Public Health, Fudan University, Shanghai, China ${ }^{2}$ Department of Epidemiology, Shanghai Key Laboratory of Meteorology and Health, Shanghai, China

${ }^{3}$ Department of Epidemiology, Key Laboratory of Public Health Safety, Ministry of Education, Shanghai, China

${ }^{4}$ Department of Epidemiology, Collaborative Innovation Center of Social Risks Governance in Health, Shanghai, China

Correspondence to Professor Weibing Wang; wwb@fudan.edu.cn

\begin{abstract}
Objectives To provide cost burden estimates and long-term trend forecast of mental disorders that need hospitalisations in Shanghai, China.

Design Daily hospital admissions and medical expenditures for mental disorder hospitalisations between 1 January 2011 and 31 December 2015 were used for analysis. Yearly total health expenditures and expenditures per hospital admission for different populations, as well as per-admission-per-year medical costs of each service for mental disorder hospitalisations, were estimated through data from 2015. We also established time series analyses to determine the long-time trend of total direct medical expenditures for mental disorders and forecasted expenditures until 31 December 2030.

Setting Shanghai, China.

Participants Daily hospital admissions for mental disorders of registered residents living in all 16 districts of Shanghai, who participated in workers' basic medical insurance or the urban residents' basic medical insurance $(\mathrm{n}=60306)$.
\end{abstract}

Results From 2011 to 2015, there were increased yearly trends for both hospitalisations (from 10919 to 14 054) and total costs (from US\$23.56 to 42.13 million per year in 2015 currency) in Shanghai. Cost per mental disorder hospitalisation in 2015 averaged US\$2998.01. Most direct medical costs were spent on medical supplies. By the end of 2030, the average cost per admission per month for mental disorders was estimated to be US\$7394.17 (95\% CI US\$6782.24 to 8006.10) for mental disorders, and the total health expenditure for mental disorders would reach over US $\$ 100.52$ million $(95 \% \mathrm{Cl}$ US\$92.20 to 108.83 million) without additional government interventions.

Conclusions These findings suggest total health expenditures for mental disorders in Shanghai will be higher in the future. Effective measures should be taken to reduce the rapid growth of the economic burden of mental disorders.

\section{BACKGROUND}

Mental disorders are generally characterised by a combination of abnormal thoughts, perceptions, emotions, behaviour and relationships with others. The WHO has estimated that the burden of mental disorders continues to grow with significant impacts on health, major social and economic

\section{Strengths and limitations of this study}

Time series models were established to determine the long-time trend of total direct medical expenditures and forecast expenditures in the future.

- Few studies used time series models to analyse medical expenditures for mental disorder hospitalisations in developing countries.

- The study population were for residents in one of the most populous and advanced cities in China, possibly affecting the effectiveness of extrapolation.

- The study is an ecological study which makes it difficult to find the association between medical expenditures and demographic and clinical characteristics.

consequences in all countries of the world. ${ }^{1} \mathrm{~A}$ recent study estimated to have 105.9 million people with mental and substance-use disorders in 2015 over the world, increased by $14.30 \%$ compared with $2005 .^{2}$ It was estimated that the global burden of diseases caused by mental disorders would reach about $15 \%$ by 2020 , much of which would occur in low-income and middle-income countries. ${ }^{3}$ Depression alone accounted for $4.3 \%$ of the global burden of disease and is among the largest single causes of disability worldwide (11\% of all years lived with disability globally), particularly for women. ${ }^{4}$ As for the cost, the global cost of mental health conditions in 2010 was estimated at US $\$ 2.5$ trillion, and it will reach US $\$ 6.0$ trillion by $2030 .^{5}$ Another study showed that the total cost for all disorders of the brain in 2010 reached $€ 798$ billion in Europe, of which the cost for mood disorders ranked first, reaching $€ 113$ billion. ${ }^{6}$ Several studies estimated that the cost on mental disorder problem in London was estimated at $£ 252$ million in 2009 , and the mean total mental health service costs per patient per year reached $£ 6823$ between 2007 and 2012. ${ }^{78}$

In China, the treatment of mental disorders mainly includes drug treatment, behaviour therapy, work therapy, recreation treatment, psychotherapy and diet therapy, 
among which medication is the most common method, ${ }^{9}$ and the number of hospitalisation admission for psychiatric patients reached 1.6 million in 2015. ${ }^{10} \mathrm{~A}$ number of studies estimated that the prevalence of mental disorder had increased in many cities these years. ${ }^{11-13}$ In 2011, the total hospitalisation expenditures of mental disorders per admission reached 10522 Chinese Yuan (CNY) in a certain province of China, accounting for $48.2 \%$ of the per capita disposable income of urban residents and $151 \%$ of the per capita disposable income of rural residents. ${ }^{1415}$

Previous studies have focused on mental disorder, but most of these projections using data from developed countries, such as the USA and European countries. ${ }^{16}{ }^{17} \mathrm{Few}$ projections of costs for mental disorders are currently unavailable in China, making the trend of costs for mental disorders uncertain. In these years, the development of epidemic modelling makes possible the forecasting of the economic burden related to mental disorders. ${ }^{18}$ Time series models have been widely used in disease management and expenditure prediction, for the greater ability to predict and a wider applicability than non-temporal techniques. ${ }^{19} 20$

Our study was performed to develop a time series model with a 15-year forecast of mental disorders hospitalisation costs in Shanghai. The projections serve as an illustration of what is likely to occur in mental disorders admission, and related costs if no change to current policy is made and no further action is taken to reduce the health and economic burden of mental disorders. These projections will allow to provide a useful baseline to gauge the success of current and future mental disorder policy.

\section{Methods}

\section{Study population}

The study population included 16.1 million registered residents living in all 16 districts of Shanghai, who participated in workers' basic medical insurance or the urban residents' basic medical insurance, excluding those with new rural cooperative medical insurance or commercial health insurance. Because people covered only by commercial health insurance accounted for only approximately $7.6 \%$ of all population as a supplementary for the basic health insurance in China, ${ }^{21}$ most of the residents were included in this study.

\section{Data collections and measures}

Data of Daily hospital admissions and medical expenditures for mental disorder hospitalisations between 1 January 2011 and 31 December 2015 were obtained from the Shanghai Health Insurance Bureau (SHIB). The SHIB is a government agency that administers the Shanghai Health Insurance System, and all public hospitals, including 1435 public hospitals (1134 primary hospitals, 226 secondary hospitals and 75 tertiary hospitals) in this city are under contract with this system. It was estimated that by the end of 2011, the proportion of private hospitals in Shanghai was about $42.52 \%$, with the beds of private hospitals accounting for approximately $7.20 \%$ of all beds. ${ }^{22}$ As most of the private hospitals were not included in the social health insurance, they were not included in our analysis; computerised hospital admissions were maintained at each contracted hospital and sent to the SHIB through an internal network system.

The numbers and direct medical expenditures of daily mental disorder hospitalisations were aggregated by sex and age. Mental disorders were diagnosed by professional psychiatrists, and all hospitalisations during the period of this study of mental disorders which were classified by the WHO International Classification of Diseases Revision 10 (ICD-10) codes (F0-F99) were included, mainly including manic disorder, depression and childhood autism. In this study, the direct medical costs included diagnostic testing, treatment, prescription drugs and medical supplies for treating mental disorder and any related complications during hospitalisation. The costs for each type of service were obtained from individual admission records of each hospital.

Patient records were de-identified prior to analysis; then the daily aggregated admissions to each hospital and costs of mental disorder hospitalisations were calculated and used to conduct the final analysis. Cost data were collected by identifying admissions with a certain disease and getting the cost in medical records. The total costs were calculated by aggregating the cost of each admission. The authors did not access to individual patient information prior to personal privacy protection and data aggregation, and none had any interactions with the patients involved in this study, so personal IDs were not available. We only described the characteristics of the study groups. Neither ethics review nor informed consent was required for the current analysis. An exemption from ethical review has been approved by the Ethics Committee of School of Public Health, Fudan University.

\section{Statistical analysis}

All statistical analyses were performed using IBM SPSS Statistics V.22. Categorical variables were presented as numbers and percentages. Descriptive data analyses were performed to explain the demographic and clinical characteristics of the study population, including sex distribution, age group and type of insurance. Total admissions and expenditures per year during the study period were calculated to determine the temporal pattern of mental disorder hospitalisations. All the expenditures were transferred to US\$ (exchange rate: $1 \$=6.2 \mathrm{CNY}$, Bank of China, January 2015).

\section{Prevalence-based cost estimation}

Data from 2015 were used to estimate prevalence-based costs, including yearly total health expenditures and expenditures per hospital admission for two types of population, as well as per-admission-per-year medical costs of each service for mental disorder hospitalisations in 2015 . The total costs were calculated by multiplying 
the total number of admissions for mental disorders in a given period with their mean cost in the same period. The employed population included adults who had a stable job and retirees, while the unemployed population included adults who did not have a stable job, people $<18$ years old and college students aged $>18$ years.

\section{Projections of direct medical costs}

Time series autoregressive integrated moving average (ARIMA) modelling is one of time series models, and can be accomplished in identification, estimation and diagnostic steps. ${ }^{23}$ In epidemiological studies, ARIMA models have been widely used to predict the incidence of infectious diseases and numbers of outpatients. ${ }^{24}{ }^{25}$ As well as the exponential smoothing method, ARIMA models can also be used to predict average costs of hospitalisation ${ }^{26}$ and costs of therapeutic method. ${ }^{27}$

Time series analyses were performed to determine the long-term trend of total direct medical expenditures for mental disorders and two types of population. Costs for mental disorders from 2011 to 2015 were adjusted to the CNY value in 2015, based on the Medical Care Consumer Price Indices data from the National Bureau of Statistics of $\mathrm{China}^{28}$ and then transferred to US\$. The average hospitalisation costs per admission of every month were calculated by dividing the monthly costs by the number of admissions that month. ARIMA time series models were first used to fit the data according to similar references. ${ }^{29}$ Data were assorted to detrend the time series and fit with $\mathrm{AR}$ and MA terms based on autocorrelation function and partial autocorrelation function plots. Identification of the correct fit was based on the results of parameter estimates, and the best model was based on the normalised Bayesian Information Criterions value. The time series models were then used to forecast the average expenditures per month per admission until 31 December 2030.

In projecting the average costs per admission per month for mental disorders, we assumed the same changes in rates of population increase and treatment patterns (medicines and treatment) before and after 2015, thus reflecting the increases in hospitalisation admissions and direct medical costs. In addition, as there were few adjustments to the basic payment patterns and populations covered by medical insurance from 2011 to 2015, we assumed no change in policy or health insurance coverage over the period to 2030. We multiplied the estimated total hospitalisation admissions by the costs per admission to estimate the yearly total expenditure, and calculate the total hospitalisation admissions according to the estimated population size. We assumed that hospitalisation rates would remain the same as data of this study in 2015 .

\section{Prediction effect of models}

Population size can affect predictions of expenditures for mental disorders. Thus, this study included a one-way sensitivity analysis to determine the effects of increased population. A report released by Shanghai Municipal
Table 1 Summary statistics of admissions for patients hospitalised with mental disorders in Shanghai, 2011-2015

\begin{tabular}{lcc}
\hline & Number & $\%$ \\
\hline All & 60306 & \\
Sex & & \\
$\quad$ Man & 30292 & 50.23 \\
$\quad$ Woman & 30014 & 49.77 \\
\hline Age (year) & & \\
$\quad<45$ & 14296 & 23.71 \\
\hline $45-65$ & 24759 & 41.06 \\
\hline $65-75$ & 7381 & 12.24 \\
\hline$\geq 75$ & 13870 & 23.00 \\
Insurance type & & \\
$\quad$ Employed & 51815 & 85.92 \\
$\quad$ Unemployed & 8491 & 14.08 \\
\hline
\end{tabular}

Health and Family Planning Commission predicted the yearly population of Shanghai with three schemes. ${ }^{30}$ The low scheme presumed the policy that every couple only have one child would keep till 2030; the middle scheme presumed that every couple will have no more than two children; and the high scheme presumed that couples could have more than two children. As Chinese government introduced the policy that allowed couples who had only one child could have a second child in early 2016, we chose the middle scheme as the main scenario to estimate the total expenditure, while the other two were used for the prediction effect of models.

\section{RESULTS}

\section{General characteristics of the study population}

Admissions for patients hospitalised with mental disorders distributions by gender, age and insurance type are summarised in table 1 . Yearly cumulative hospital admissions and direct medical expenditures from 2011 to 2015 are shown in figure 1. During this period (1826 days), a total of 60306 hospital admissions for mental disorders were recorded in Shanghai, a mean of 33.0 per day. From 2011 to 2015, there was an increased trend for both hospitalisation admissions (from 10919 to 14054 per year) and total costs (from US $\$ 23.56$ to 42.13 million per year). The direct medical expenditures of both employed population and unemployed population presented an increased trend.

\section{Cost estimation for 2015}

Annual medical expenditures and yearly health expenditures per admission for mental disorder hospitalisations in 2015 are shown in table 2. Costs per admission for mental disorder hospitalisation in 2015 averaged US\$2998.01. Costs of hospitalisation for patients with different ages, sex and type of medical insurance were different. Expenditures per admission for mental disorder were higher for 


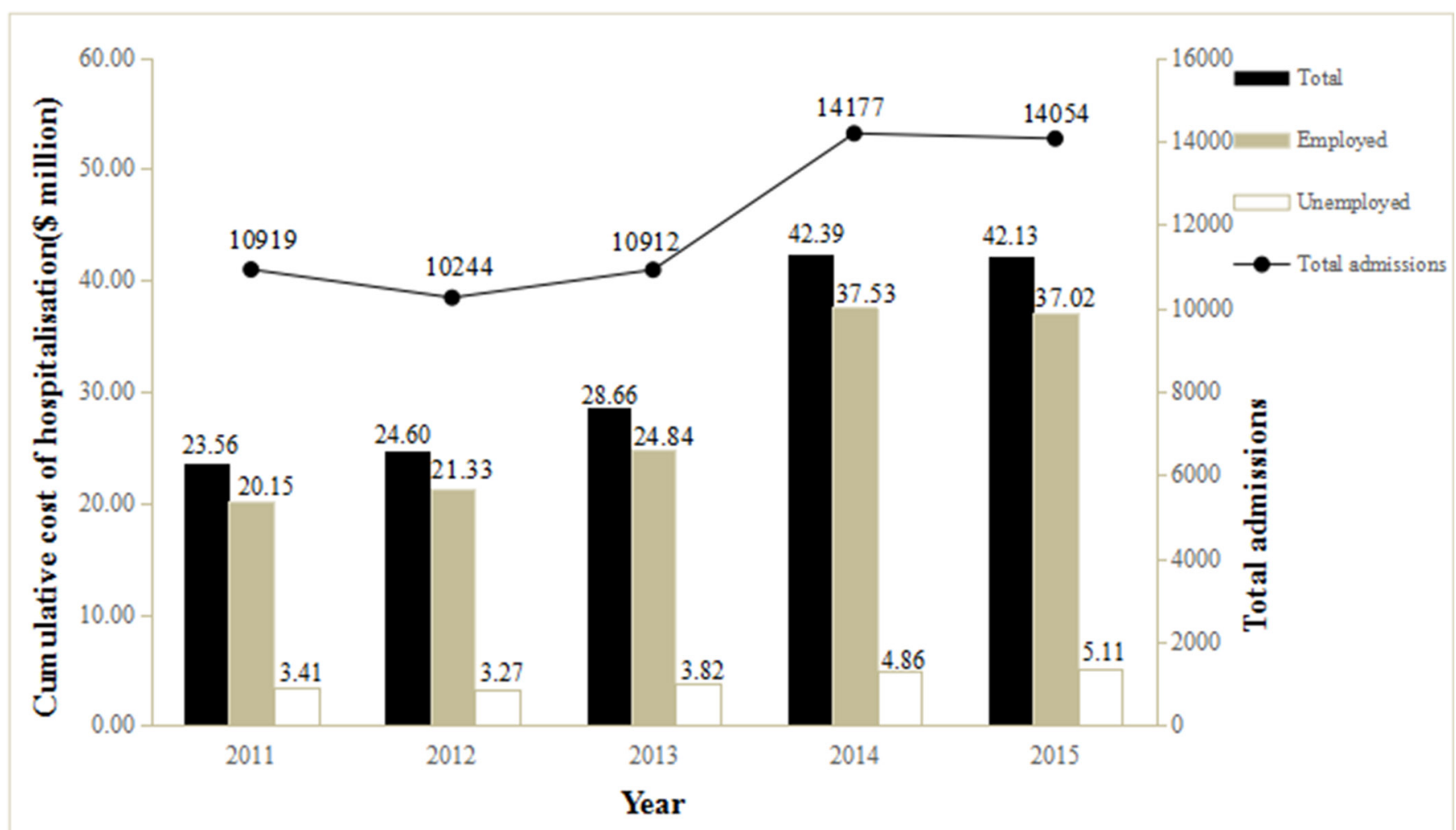

Figure 1 Yearly cumulative admissions and expenditures for patients hospitalised with mental disorder in Shanghai (US\$ million). The line with symbol ' $\bullet$ ' represents the yearly admissions for patients hospitalised, and the black bars represent the yearly total expenditures for total population, while grey bars represent expenditures for employed population and white bars represent expenditures for unemployed population.

men than women, except for unemployed individuals and higher for employed than for unemployed individuals. For the employed population, the major expenditure was for patients aged $65-75$ years, although expenditures for unemployed population were higher in patients aged $<45$ years than in other age groups. For both the employed and unemployed population, most direct medical costs were spent on medical supplies (table 3).

Time series analysis of average costs for mental disorder A sequence chart of data from 2011 to 2015 showed that hospitalisation admissions for mental disorder presented an upward trend and seasonal variations. Table 4 shows the models and their performance. The $p$ values of the Ljung-Box test were all over 0.05 , indicating that the residuals from the models had no significant autocorrelation, which shows that these models fit the data. The results of forecasting, including observed, fit and forecast values, and credibility intervals are shown in figure 2 . The costs for all population, employed population and unemployed population showed increasing trends. By the end of 2030, the average costs per admission per month were estimated to be US\$7394.17 (95\% CI US\$6782.24 to 8006.10$)$ for all population, US\$7354.72 (95\% CI

Table 2 Annual medical expenditures for mental disorder hospitalisations in Shanghai, 2015 (US\$)

\begin{tabular}{|c|c|c|c|c|c|c|}
\hline & \multicolumn{3}{|c|}{ Yearly total health expenditures (thousands of US\$) } & \multicolumn{3}{|c|}{ Yearly health expenditures per admission (US\$) } \\
\hline & All & Employed & Unemployed & All & Employed & Unemployed \\
\hline All & 42134.02 & 37024.61 & 5109.41 & 2998.01 & 3021.92 & 2835.41 \\
\hline \multicolumn{7}{|l|}{ Sex } \\
\hline Man & 22017.05 & 19410.02 & 2607.02 & 3108.87 & 3160.21 & 2773.43 \\
\hline Woman & 20116.97 & 17614.59 & 2502.38 & 2885.39 & 2882.91 & 2903.00 \\
\hline \multicolumn{7}{|l|}{ Age (year) } \\
\hline$<45$ & 8840.83 & 5758.80 & 3082.03 & 2929.37 & 2890.96 & 3003.92 \\
\hline $45-65$ & 16945.48 & 15873.11 & 1072.37 & 2999.73 & 3019.42 & 2735.64 \\
\hline $65-75$ & 6515.87 & 6182.60 & 333.27 & 3085.17 & 3141.56 & 2314.41 \\
\hline$\geq 75$ & 9831.84 & 9210.11 & 621.73 & 3002.09 & 3034.63 & 2590.56 \\
\hline
\end{tabular}


Table 3 Direct medical expenditures for mental disorder hospitalisations per admission in Shanghai, 2015 (US\$)

\begin{tabular}{llllllcr} 
& $\begin{array}{l}\text { Total } \\
\text { expenditure }\end{array}$ & $\begin{array}{l}\text { Diagnostic } \\
\text { testing }\end{array}$ & $\begin{array}{l}\text { Blood transfusion and } \\
\text { oxygen therapy }\end{array}$ & $\begin{array}{l}\text { Medical } \\
\text { supplies }\end{array}$ & Medication & $\begin{array}{l}\text { Surgical } \\
\text { materials }\end{array}$ & $\begin{array}{l}\text { Other } \\
\text { expenditure }\end{array}$ \\
\hline All & 2998.01 & 579.19 & 22.83 & 1296.20 & 678.83 & 90.39 \\
Employed & 3021.92 & 585.41 & 25.10 & 1287.66 & 704.06 & 85.89 \\
Unemployed & 2835.41 & 536.88 & 7.37 & 1354.25 & 507.26 & 120.92 & 308.73 \\
\hline
\end{tabular}

Medical supplies mainly included patient meals, care and supplement treatments, such as physical therapy and psychotherapy.

US\$6635.07 to 8074.36) for employed population and US\$7206.24 (95\% CI US $\$ 6222.27$ to 8191.02$)$ for unemployed population. Based on the main scenario, the numbers of hospitalisations for mental disorder would be 15738 , making the total expenditure US\$110.95 million (95\% CI US\$ 101.32 to 120.58 million) in 2030.

\section{Prediction effect of models}

By multiplying the predicted average costs with different population schemes, we predicted the annual total hospitalisation expenditure (figure 3). Based on the low and high scenarios, the numbers of hospitalisations for mental disorders would be 15540 and 15959 , respectively, in 2030, making the total expenditure US\$109.55 million (95\% CI 100.05 to 119.06 million) and US $\$ 112.51$ million (95\% CI 102.75 to 122.28 million), respectively.

\section{DISCUSSION}

The results of our study showed that both the hospitalisation admissions of mental disorders and expenditures associated with hospitalisation for these diseases increased from 2011 to 2015 , with the increasing proportions at $28.7 \%$ and $78.8 \%$, respectively. However, the total health expenditure in Shanghai during this period increased by just $46.44 \% .{ }^{1531}$ And the cost per admission for mental disorder hospitalisation was $17 \%$ higher than the average hospitalisation cost for all patients in 2015 in Shanghai, which was US\$2570.27. ${ }^{10}$ The increase in total expenditures was the result of a combination of the increase in prices and the number of hospitalisations, and the former $(49.49 \%)$ contributed more than the latter $(36.51 \%)$. About two-thirds of hospitalisation expenditures for mental disorders in Shanghai were medical supplies and medication. According to the predictive model, the burden of mental disorders is likely to increase in Shanghai over the next 15 years, and the total health expenditures for mental disorders will continue to increase, to over US\$110.95 million in 2030 , if there are no additional government interventions.

Many previous costs-of-illness studies on mental disorders have focused on the burden of one or several specific diseases in developed countries. In the USA, the cost of condition with mental disorders reached $\$ 201$ billion in 2013, topping the list of the most costly conditions. ${ }^{32}$ In France, hospitalisation costs amounted to $£ 8.3$ billion in 2007, accounting for $64 \%$ of total healthcare costs for mental disorders. ${ }^{17}$ In Canada, it was estimated that nearly 1.9 million people have been diagnosed with mental illness and a further 1.6 million people are undiagnosed in 2003, and the average medical cost per capita was $\$ 2515$ for the diagnosed and $\$ 1442$ for the undiagnosed. ${ }^{33}$ It is difficult to assess the total burden of mental disorders in the developing world because of the scarce epidemiological data, because only a few of studies have estimated the economic burden on the developing countries. In China, a study including 5439 cases in Beijing estimated that the hospitalisation cost per patient increased from $\$ 1618.9$ to $\$ 2380.7$, between 2008 and $2010 .{ }^{34} \mathrm{~A}$ study based on patients in psychiatric hospital of Shandong Province of China estimated that the hospitalisation cost per discharge rose from $\$ 558.9$ to $\$ 1431.4$, between 2005 and 2011. ${ }^{35}$ Our results, which showed that cost per admission for mental disorder hospitalisation increased from US\$2157.71 in 2011 to US\$ 998.01 in 2015, had a similar trend with these estimations.

We also used an ARIMA model to predict expenditures for mental disorders, the results showed that both total medical expenditures and average costs for mental disorder hospitalisations of all types of population tended to increase. The global direct cost of mental disorders were estimated to be US $\$ 823$ billion in 2010 , with this amount estimated to rise to US $\$ 1995$ billion in 2030 , and the amount in low-income and middle-income countries would increase from US $\$ 287$ billion to US $\$ 697$ billion, ${ }^{5}$

Table 4 Performance of the forecasting models

\begin{tabular}{llccc}
\hline & Model & Ljung-Box p value & MAE & MAPE \\
\hline Total population & ARIMA $(1,0,0) \times(1,1,0)_{12}$ & 0.920 & 99.971 & 3.871 \\
Employed population & ARIMA $(1,0,0) \times(1,1,0)_{12}$ & 0.958 & 112.404 & 4.250 \\
Unemployed population & ARIMA $(1,0,1) \times(1,1,0)_{12}$ & 0.426 & 157.391 & 6.599 \\
\hline
\end{tabular}

For the measures of MAE and MAPE, a smaller value indicates better model performance. However, there is no absolute standard to which these values can be compared directly.

ARIMA, autoregressive integrated moving average, MAE, mean absolute error, MAPE, mean absolute percentage error. 

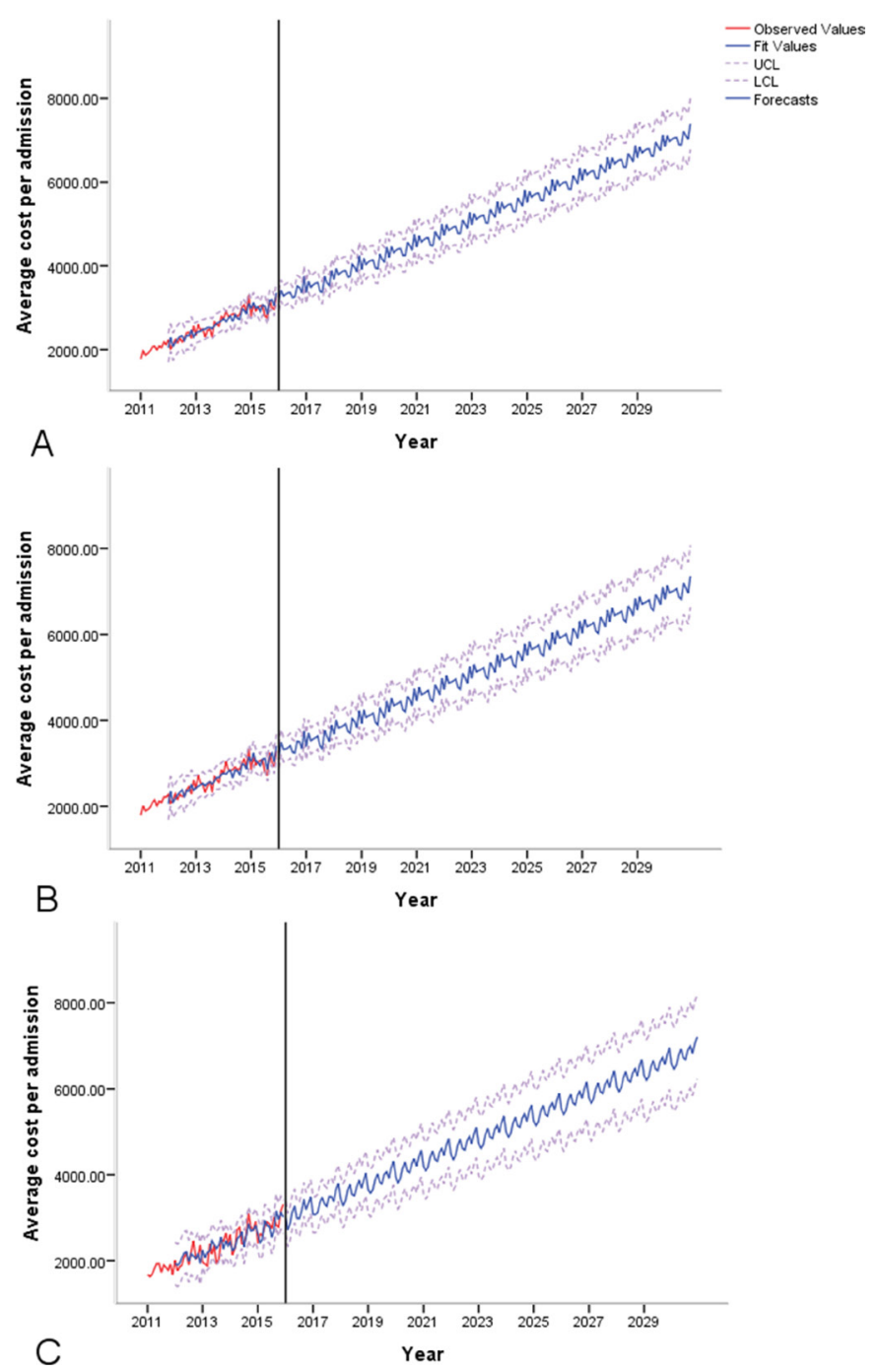

Figure 2 Forecasted costs for mental disorders per month per admission (US \$). The red lines show observed values, while the blue lines show fit values (before the reference line) and projected values (after the reference line), and the light pink lines show $95 \% \mathrm{Cl}$ of the series: $(A)$ all population; $(B)$ employed population and $(C)$ unemployed population. UCL, upper control limit. LCL, lower control limit.

showing a similar trend with our results. With changes in treatment of mental disorders, psychological counselling, music therapy, skills training and other treatment modalities were used more and more frequently, which would increase cost of treatment ${ }^{36}$; and there was a growing trend of the bed and care costs which reflected the medical workers' technology and services these years, ${ }^{37}$ these might explain the steady growth trend of the average costs per admission per month. However, this trend was also likely to be caused by social demographic changes. ${ }^{2}$ What is more, our results also showed that the average costs per admission per month of early 2013 and early 2015 decreased significantly. Decline in 2013 could be explained by the establishment of community-based management system for persons with mental illness in Shanghai in 2012, so patients could get medicine and basic treatment in the community. ${ }^{38}$ At the end of 2014, Shanghai Municipal People's Congress amended the Regulations of Shanghai Municipality on Mental Health, ${ }^{39}$ including the strengthening of the management of medical institutions of mental illness, refinement of the patient's medication and treatment standards, which might cause the decline in 2015.

The increasing cost of hospitalisation for mental disorders can lead to many serious problems. As mental disorders is still perceived as an individual or family problem, instead of a policy challenge with significant economic and political implications, higher hospitalisation costs will lead to greater economic burden for patients and their families, and this may result in some patients cannot complete the treatment and even cannot be hospitalised for treatment. ${ }^{40}$ However, as the number of individuals affected by mental illness increase substantially, more people will be affected by the higher hospitalisation costs, which must lead to a certain group of social problems. ${ }^{4142}$ The results of many studies showed that indirect costs caused by mental disorders were more than direct costs,${ }^{56}$ but indirect costs were more difficult to calculate directly and accurately, and because of the lack of data for costs-of-illness studies on mental disorders in developing countries, policy changes cannot be supported by clear data, ${ }^{43}$ so results of this study can be a reference for policy-makers in some cities of China and cities which have similar conditions in other countries.

This study had several limitations. First, because the effects of policy changes were hard to quantify, policy was not considered influential in the models. We also assumed no change in policy over the period, and the economic growth of China till 2030 keeps the same trend with the period 2011-2015. Second, the study population was for residents who registered the Shanghai Health Insurance System, with relatively sound economic conditions compared with rural residents, thus possibly introducing a selection bias. Also, Shanghai is one of the most populous and advanced cities in China, therefore the results of this city may be different from others, thereby possibly affecting the effectiveness of extrapolation. Third, it was estimated that the proportion of people aged $>65$ years would be slightly increased by 2030 in Shanghai, ${ }^{44}$ the total expenditures estimated based on data in 2015 in this projection might be a little higher than the actual situation. Fourth, as our data were restricted to inpatient treatment in public hospitals, expenditures of outpatient treatment and private hospitals were unavailable; our estimates might have been underestimated from a real economic burden of mental disorders. Fifth, the expenditure would likely be corresponding to the changes of treatment patterns (eg, improvement in medical technology and treatments) in a longer period that unfortunately is difficult to be quantified at this stage, which brings an uncertainty for a long-term projection. Finally, as many hospitalisation admissions were not classified into any specific mental disorder, we could not analyse the cost of a particular mental disorder, and this caused great difficulties in our 


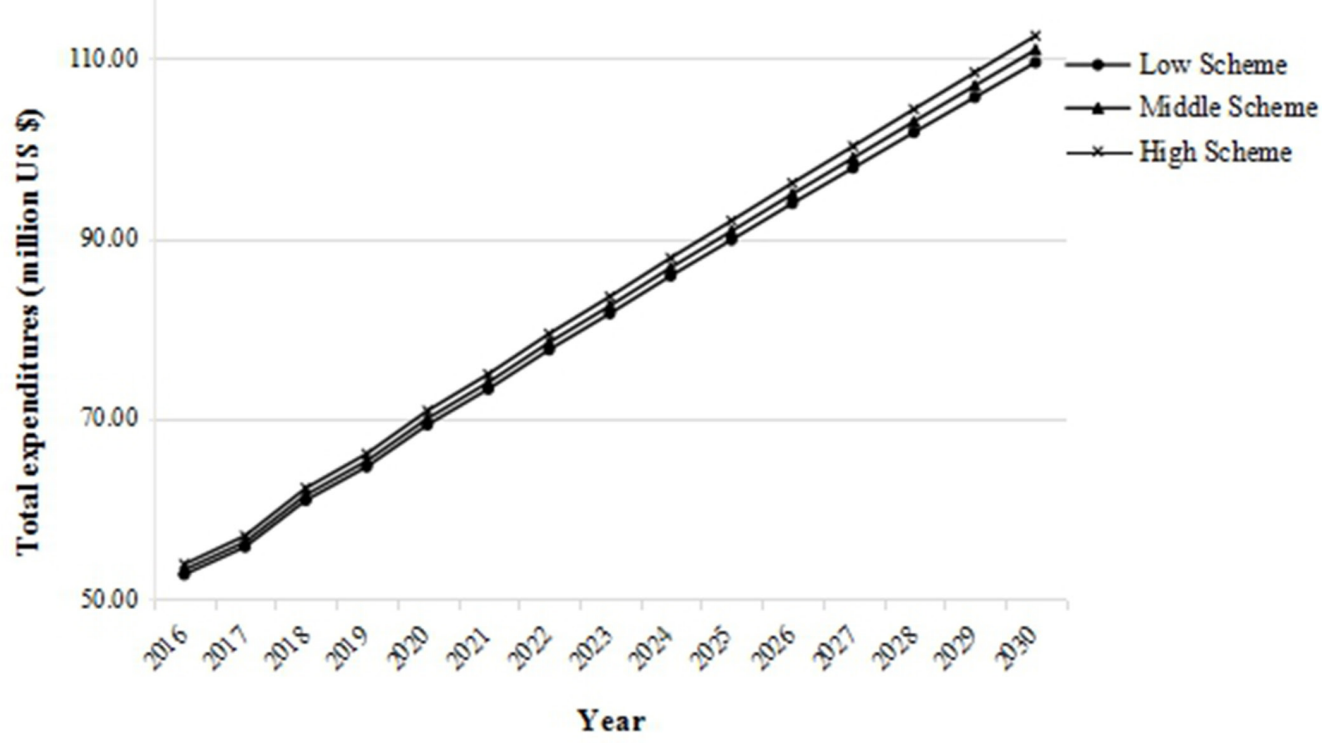

Figure 3 Prediction results of hospitalisation expenditure based on different population scheme (million US\$). The line with the symbol ' $X$ ' represents the annual total hospitalisation expenditure of the high population scheme, while the line with the symbol ' $\boldsymbol{\Delta}$ ' and the line with the symbol ' $\boldsymbol{O}$ ' represent the expenditure of the middle scheme and the low scheme, respectively.

analysis of the composition of the total cost of hospitalisation for all mental disorders.

\section{CONCLUSIONS}

In conclusion, this study analysed medical expenditures for mental disorders in Shanghai and found increasing trends in costs of hospitalisation, both for employed and unemployed population. Moreover, our models predicted that these costs will continue to increase in the following decades. These findings suggest that the burden of mental disorders will be higher in the future. Therefore, a greater focus on prevention may alter these future mental disorder projections. These results should be a valuable future resource to both researchers on economic effects of mental disorders and policy-makers.

Contributors WC, SW and QW, conducted the study and performed the data analysis. WC, drafted the manuscript. WW, reviewed and edited the manuscript, and conceived the study and contributed to the study design. All authors: read and approved the final manuscript.

Funding This study was funded by the National Natural Science Foundation of China (grant no. 81673233) and the Shanghai Municipal Health and Family Planning Commission (grant no. GWTD2015S05).

Competing interests None declared.

Provenance and peer review Not commissioned; externally peer reviewed.

Data sharing statement № additional data are available.

Open Access This is an Open Access article distributed in accordance with the Creative Commons Attribution Non Commercial (CC BY-NC 4.0) license, which permits others to distribute, remix, adapt, build upon this work non-commercially, and license their derivative works on different terms, provided the original work is properly cited and the use is non-commercial. See: http://creativecommons.org/ licenses/by-nc/4.0/

(C) Article author(s) (or their employer(s) unless otherwise stated in the text of the article) 2017. All rights reserved. No commercial use is permitted unless otherwise expressly granted.

\section{REFERENCES}

1. World Health Organization. Mental disorders: WHO media centre 2016. www.who.int/mediacentre/factsheets/fs396/en/

2. GBD 2015 Disease and Injury Incidence and Prevalence Collaborators. Global, regional, and national incidence, prevalence, and years lived with disability for 310 diseases and injuries, 19902015: a systematic analysis for the Global Burden of Disease Study 2015. Lancet 2016;388:1545-602.

3. World Health Organization. The global burden of disease: 2010 update. Geneva: WHO, 2011.

4. World Health Organization. Comprehensive mental health action plan 2013-2020. Geneva: World Health Organization, 2013. http://apps. who.int/gb/ebwha/pdf_files/WHA66/A66_R8-en.pdf

5. World Economic Forum, The Harvard School of Public Health. The global economic burden of non-communicable diseases. Geneva: World Economic Forum, 2011.

6. Gustavsson A, Svensson M, Jacobi F, et al. Cost of disorders of the brain in Europe 2010. Eur Neuropsychopharmacol 2011;21:718-79.

7. Kane E, Reeder N, Keane K, et al. A cost and economic evaluation of the Leeds personality disorder managed clinical network-A service and commissioning development initiative. Personal Ment Health 2016;10:169-80.

8. Cary M, Oram S, Howard LM, et al. Human trafficking and severe mental illness: an economic analysis of survivors' use of psychiatric services. BMC Health Serv Res 2016;16:284.

9. Mingsheng H. Handbook of psychiatric disorders. Beijing: People's Medical Publishing House, 2010.

10. The Ministry of Health of the People's Republic of China. China health statistical yearbook 2015. Beijing: Peking Union Medical College press, 2016.

11. Phillips MR, Zhang J, Shi Q, et al. Prevalence, treatment, and associated disability of mental disorders in four provinces in China during 2001-05: an epidemiological survey. Lancet 2009;373:2041-53.

12. Shi QC, Zhang JM, Xu FZ, et al. [Epidemiological survey of mental illnesses in the people aged 15 and older in Zhejiang Province, China]. Zhonghua Yu Fang Yi Xue Za Zhi 2005;39:229-36.

13. Zhang W, Shen Y, Li S. Epidemiological survey of mental disorders in seven areas of China (Chinese)[J]. J Of Psychiatr 1998;31:69.

14. Jun Fang XU, Feng Hua YU, Jian W. Analyzing the hospitalization expense and management status of severe mental illness (Chinese) [J]. Chin Health Econ 2013;10:53-6.

15. The Ministry of health of the people's Republic of China. China health statistical yearbook 2011. Beijing: Peking Union Medical College press, 2012.

16. Greenberg PE, Fournier AA, Sisitsky T, et al. The economic burden of adults with major depressive disorder in the United States (2005 and 2010). J Clin Psychiatry 2015;76:155-62. 
17. Chevreul K, Prigent A, Bourmaud A, et al. The cost of mental disorders in France. Eur Neuropsychopharmacol 2013;23:879-86.

18. Zhang $X$, Zhang T, Young AA, et al. Applications and comparisons of four time series models in epidemiological surveillance data. PLOS One 2014;9:e88075

19. Miller LS, Martin BC. Current and future forecasts of service use and expenditures of medicaid-eligible schizophrenia patients in the state of Georgia. Schizophr Bull 2004;30:983-95.

20. Sato RC. Disease management with ARIMA model in time series. Einstein 2013;11:128-31.

21. Dong K. Medical insurance system evolution in China. China Economic Review 2009;20:591-7.

22. Su P, Tian W, Jin C, et al. The development trend of private medical institutions in Shanghai (Chinese)[J]. Chin Health Resour 2014;6:436-8.

23. Nelson BK. Time series analysis using autoregressive integrated moving average (ARIMA) models. Academic Emergency Medicine 1998;5:739-44

24. Liu Q, Liu X, Jiang B, et al. Forecasting incidence of hemorrhagic fever with renal syndrome in China using ARIMA model. BMC Infect Dis 2011;11:218.

25. Chen $\mathrm{CF}, \mathrm{Ho} \mathrm{WH}, \mathrm{Chou} \mathrm{HY}$, et al. Long-term prediction of emergency department revenue and visitor volume using autoregressive integrated moving average model. Comput Math Methods Med 2011;2011:1-7.

26. Wang S, Petzold M, Cao J, et al. Direct medical costs of hospitalizations for cardiovascular diseases in Shanghai, China: trends and projections. Medicine 2015;94:e837.

27. Padilla A, Ferriols R, Alós M. [A time series analysis of the cost of the most common drug treatment groups in an intensive care unit]. Farm Hosp 2007:31:307-10.

28. National Bureau of Statistics of China. National data-Medical care consumer price indices (Chinese), 2014.

29. Martin BC, Miller LS, Kotzan JA. Antipsychotic prescription use and costs for persons with schizophrenia in the 1990s: current trends and five year time series forecasts. Schizophr Res 2001;47:281-92.

30. Sun M. The trend of the future population changing in Shanghai (Chinese). 2003 http://http://www.docin.com/p-52437950.html

31. The Ministry of health of the people's Republic of China. China health statistical yearbook 2016. Beijing: Peking Union Medical College press, 2017.
32. Roehrig C. Mental disorders top the list of the most costly conditions in the United States: \$201 Billion. Health Aff 2016; $35: 1130-5$.

33. Lim KL, Jacobs $\mathrm{P}$, Ohinmaa A, et al. A new population-based measure of the economic burden of mental illness in Canada. Chronic Dis Can 2008;28:92-8.

34. Wang Bingjie LX. Analysis of factors influencing hospitalization expenses of 5439 psychiatric inpatients (Chinese). Chin J Hospital Stat 2013;20:30-6.

35. Xu J, Wang J, Wimo A, et al. The economic burden of mental disorders in China, 2005-2013: implications for health policy. BMC Psychiatry 2016;16:137

36. Xu J, Yu F, Wang J. Analysis of hospitalization expenditure and influencing factors of elderly patients with mental illness(Chinese). Chin J Health Stat 2014;31:475-7.

37. Song $\mathrm{C}, \mathrm{Ma} \mathrm{J}$, Cui $\mathrm{Z}$, et al. Analysis to the structure of insured hospitalization cost in insured schizophrenia inpatients (Chinese)[J]. Chin J Health Stat 2011;28:533-6.

38. Zhang Q, Chen H, Ju K, et al. Cross-secitonal evaluaiton of the adequacy of guardianship by family members of community-residing persons with mental disorders in Changning District, Shanghai[J]. Shang Archiv of Psychiatr 2015;1:18-26.

39. Shanghai Municipal People's Congress. Regulations of Shanghai municipality on mental health, 2014. http://www.spcsc.sh.cn/ shrdgzw/node4/node22/node36/n116/u1ai58838.html

40. Insel TR, Collins PY, Hyman SE. Darkness Invisible The Hidden Global Costs of Mental IIIness[J]. Foreign Affairs 2015;94:127-35.

41. Dewa CS, Loong D, Bonato S. Work outcomes of sickness absence related to mental disorders: a systematic literature review. BMJ Open 2014;4:e5533e005533

42. Silva Junior JS, Fischer FM. [Disability due to mental illness: social security benefits in Brazil 2008-2011]. Rev Saude Publica 2014;48:186-90.

43. Whiteford H, Ferrari A, Degenhardt L. Global burden of disease studies: implications for mental and substance use disorders. Health Aff 2016:35:1114-20.

44. Wang D, Liu Z, Wu M, et al. Population change in Shanghai: trends, dilemmas and management strategies(Chinese). Urban Planning Forum 2015;2:40-7. 